\title{
Diferenças no Padrão da Atividade Alelopática em Espécies da FAMília LEGUMINOSAE ${ }^{1}$
}

\author{
Differences in Allelopathic Activity Patterns in Leguminosae \\ MOURÃO JÚNIOR, M. ${ }^{2}$ e SOUZA FILHO, A.P.S. ${ }^{3}$
}

\begin{abstract}
RESUMO - As inúmeras espécies de plantas que compõem a floresta amazônica podem representar excelente alternativa para fazer frente ao desafio de desenvolver a agricultura conforme as exigências da sociedade. Neste trabalho, procurou-se determinar e caracterizar o padrão de atividade alelopática em espécies da família Leguminosae, em função de variações de espécies, fonte de extratos e sensibilidade da planta receptora. Bioensaios de germinação de sementes e alongamento da radícula e do hipocótilo foram desenvolvidos em condições controladas. Os resultados indicam que as espécies estudadas não apresentaram padrão semelhante no tocante aos efeitos potenciais alelopáticos, havendo, entretanto, hierarquização no tocante à intensidade dos efeitos globais, sendo o potencial alelopático inibitório mais amplo e efetivo nas espécies Bauhinia guianensis, Bowdichia virgiloides, Parkia pendula e Platimenia reticulata. O potencial alelopático foi efetivo e mais restrito em Bauhinia macrostachya. O fator fração das plantas revelou diferenciação no padrão de atividade: para a maioria das espécies, as folhas foram a principal fonte de aleloquimicos, e para Bauhinia macrostachya e Inga edulis, a raiz. Em termos de padrão de respostas das espécies receptoras, o alongamento da radicula é mais sensivel aos efeitos dos extratos, ficando o alongamento do hipocótilo como o de menor sensibilidade. Os efeitos dos extratos foram mais intensos sobre Mimosa pudica. Esses resultados também atribuem à floresta amazônica importância como fonte de compostos químicos de interesse para o homem, o que, em si, justifica sua preservação.
\end{abstract}

Palavras-chave: alelopatia, extratos, planta daninha, inibição.

\begin{abstract}
Innumerous plant species in the Amazon forest may be an excellent alternative to meet society's demand for natural products. This work aimed to determine and characterize the pattern of allelopathic activity in species of the Leguminosae family, according to species variation, extract source, and receptor plant sensitivity. Bio assays of seed germination and radicle and hypocotyl elongation were developed under controlled conditions. The results indicated that the species studied do not present a similar pattern regarding the potential allelopathic effects; however, there is a hierarchy concerning the intensity of the global effects, with the allelopathic inhibitory potential being more extensive and effective forthe species Bauhinia guianensis, Bowdichia virgiloides, Parkia pendula and Platimenia reticulate, and more restricted and effective for Bauhinia macrostachya. The plant fraction factor showed differences in the activity pattern, with the leaves being the main source of allelochemicals formost species, and the roots, for Bauhinia macrostachya and Inga edulis. In terms of response pattern of the receptor plants, radicle elongation is more sensitive to the effects of the extracts, with hypocotyl elongation being the least sensitive. The effect of the extracts was more intense for Mimosa pudica. These results confirm the importance of the Amazon forest as a source of chemical compounds of interest to mankind, which by itselfjustifies its preservation.
\end{abstract}

Keywords: allelopathy, extracts, weed, inhibition.

1 Recebido para publicação em 18.5.2010 e na forma revisada em 17.12.2010.

2 Biólogo, M.Sc., Embrapa Amazônia Oriental. Trav. Dr. Enéas Pinheiro, S/N, 66095-100 Belém-Pará, <mmourao@cpatu.embrapa.br>; ${ }^{3}$ Engo-Agro ., Dr., Embrapa Amazônia Oriental, <apedro@cpatu.embrapa.br>. 


\section{INTRODUÇÃO}

Ao longo das últimas sete décadas, esforços consideráveis foram despendidos no sentido de detectar espécies de plantas com potencial de uso nas mais variadas atividades do homem, como medicina, cosméticos, higiene e indústria alimentar. Obviamente, o conhecimento popular e o uso medicinal de muitas espécies de plantas, especialmente pelas comunidades indígenas, por exemplo, desempenharam papel preponderante no início da pesquisa, possibilitando estudos a partir de um mínimo de informações disponiveis, o que reduziu o tempo da pesquisa e possibilitou avanços em velocidade admirável.

Adicionalmente a esses aspectos, a percepção de que essas plantas podem fornecer novas perspectivas de exploração agrícola vem se somar às inúmeras possibilidades de uso da biodiversidade, não só no tocante aos microrganismos, como também às espécies de plantas. Especificamente na região amazônica, até pela rica e diversificada biodiversidade, as espécies que compõem a floresta tropical úmida podem representar fonte impar para a descoberta de inovadoras e importantes fontes químicas para fazer frente ao desafio de se desenvolver a atividade agrícola compativel com as atuais e futuras exigências da sociedade, em relação à preservação dos recursos naturais (água e solo), da vida silvestre e uso de alimentos, na dieta dos humanos, desprovidos de resíduos de estimulantes do crescimento e de compostos tóxicos oriundos do uso de pesticidas.

Teoricamente, todas as plantas são capazes de produzir compostos altamente diversificados quimicamente, com potencial de uso no manejo de plantas daninhas. Essa especificidade pode ser detectada tanto nas plantas nativas como nas cultivadas, embora nas primeiras - até porque não passaram por processo de domesticação - tais propriedades possam ser mais auspiciosas. Identificar e selecionar, em função do grau de toxicidade, espécies de plantas com potencial para tais fins vêm se constituindo em atividade primária em muitos laboratórios em universidades e institutos de pesquisa espalhados pelo mundo. Bons exemplos são encontrados nos trabalhos de Souza Filho et al. (2005), Iqbal et al. (2004)
Borges et al. (1993), Chou (1992), Gonzáles et al. (1995) e Zhang (1993). Muitos desses trabalhos abordam, em condições de laboratório, os efeitos de extratos brutos aquosos ou mesmo hidroalcoólicos sobre a germinação de sementes e o alongamento da radícula e do hipocótilo de diferentes espécies de plantas daninhas (Tefera, 2002; Simões et al., 2008; Inoue et al., 2009).

Entre as muitas possibilidades de exploração de espécies de plantas disponíveis na floresta amazônica, destaca-se a família Leguminosae, representada por mais de 600 gêneros e 13.000 espécies, com concentração nas regiões tropicais e subtropicais (Andrade, 2003). Espécies dessa família têm se revelado promissoras como fonte de compostos químicos com alta atividade fitotóxica, sobretudo para o controle de plantas daninhas, como pode ser observado nos trabalhos de Souza Filho \& Alves (2000), Periotto et al. (2004), Duke et al. (2002), Lôbo et al. (2008), Xuan \& Tsuzuki (2002) e Kato-Noguchi (2003). Entretanto, o nivel de informação disponivel ainda está restrito a poucas espécies, quando se considera o conjunto disponivel para estudos e seleção de novas espécies com potencial para o desenvolvimento de estudos mais avançados, especialmente em relação à identificação de substâncias químicas envolvidas naquelas atividades observadas nos estudos com extratos brutos. Essa lacuna revela a necessidade de desenvolver exaustivos estudos com representantes dessa família, visando elevar o número de espécies prospectadas e o aumento do conhecimento das reais possibilidades que as espécies de Leguminosae podem representar para esse tipo de estudo.

Dessa forma, este trabalho teve por objetivos determinar e caracterizar o padrão de atividade alelopática em espécies da família Leguminosae, em função de variações de espécies, fonte de extratos e sensibilidade da planta receptora, visando a seleção de espécies para estudos mais avançados, envolvendo a identificação de aleloquímicos.

\section{MATERIAL E MÉTODOS}

Coleta de material vegetativo: folhas e raízes das espécies Bauhinia guianensis, B. macrostachya, Bowdichia virgiloides, 
Dialinum guianensis, Inga edulis, Parkia pendula, Platimenia reticulata e Swartzia multijuga (família Leguminosae) foram coletadas no Campo Experimental da Embrapa Amazônia Oriental, localizado em Belém-PA. Por ocasião da coleta, as plantas não estavam florescendo ou mesmo produzindo sementes. Posteriormente, as duas frações foram secas em estufas de circulação forçada de ar a $40{ }^{\circ} \mathrm{C}$, até peso constante. Em seguida, foram trituradas em moinho tipo faca.

Para extração, utilizou-se mistura de água e metanol, na proporção de 7:3, empregando-se três litros da solução para cada kg de material seco triturado, por período de sete dias consecutivos, substituindo-se, diariamente, a mistura por três outros litros. Sequencialmente, realizou-se a retirada da solução alcoólica, em rotavapor rotativo, e da aquosa, em liofilizador, obtendo-se, dessa maneira, o extrato bruto concentrado hidroalcoólico das respectivas frações de cada espécie.

Espécies receptoras: foram utilizadas duas das principais plantas daninhas que infestam as áreas de pastagens cultivadas da Amazônia: malícia (Mimosa pudica) e mata-pasto (Senna obtusifolia). As sementes foram coletadas em áreas de pastagens cultivadas, em fase de degradação, no município de Terra Alta-PA. Passaram por processo de limpeza e foram tratadas com vista à quebra da dormência, via imersão em ácido sulfúrico concentrado por 15 (malícia) e 20 minutos (mata-pasto).

Bioensaio de germinação de sementes: a germinação foi monitorada em períodos de 10 dias, com contagens diárias e eliminação das sementes germinadas. Foram consideradas sementes germinadas aquelas que apresentavam extensão da raiz primária igual ou superior a 2,00 mm (Juntila, 1976; Duran $\&$ Tortosa, 1985). Os testes foram realizados em câmaras tipo BOD, com temperatura constante de $25^{\circ} \mathrm{C}$ e fotoperíodo de 12 horas. Cada placa de Petri de 9,0 cm de diâmetro, forrada com uma folha de papel-filtro qualitativo, recebeu 30 sementes.

Bioensaio de alongamento da radícula e do hipocótilo: os testes foram realizados em câmaras tipo $\mathrm{BOD}$, em condições controladas de $25^{\circ} \mathrm{C}$ de temperatura constante e fotoperíodo de 24 horas. Cada placa de Petri forrada com uma folha de papel-filtro qualitativo recebeu três sementes pré-germinadas, com dois dias de germinadas; ao final de um período de 10 dias de crescimento, mediram-se os comprimentos da radícula e do hipocótilo.

Outros procedimentos experimentais: para todos os testes, empregou-se a mesma concentração de 1,0\%, adicionando-se, em cada placa de Petri, o volume de 3,0 mL, deixando-se evaporar o solvente e adicionando água destilada no volume correspondente ao evaporado. As soluções-teste foram adicionadas apenas uma vez, quando do início dos bioensaios, sendo a partir de então adicionada apenas água destilada, sempre que se fez necessário.

Delineamento experimental e análise estatistica: o delineamento experimental foi do tipo inteiramente casualizado com três repetições, tendo como tratamento testemunha a água destilada. Os valores de inibição de germinação $\left(\delta_{(g)}\right)$ e alongamento do hipocótilo $\left(\delta_{(\mathrm{h})}\right)$ e radícula $\left(\delta_{(\mathrm{r})}\right)$ das espécies receptoras, em cada um dos extratos das frações das espécies, foram analisados por meio do modelo linear geral (GLM) [1], constando do efeito das espécies e frações, bem como a interação entre estas. O modelo foi testado via teste $\mathrm{F}$, e os valores médios, dada a significância do modelo, foram contrastados segundo o teste de Tukey. Tanto no caso do teste F quanto do teste de comparação múltipla, foi adotado o nível de significância de $5 \%$.

$$
y=\mu+\alpha_{i}+\beta_{j}+(\alpha \beta)_{i j}+\varepsilon_{i j k}
$$

em que: $\mu=$ constante associada a todas as observações, tomada como média global; $\alpha_{i}=$ efeito da espécie; $\beta_{j}=$ efeito da fração; $\alpha b_{i j}=$ interação espécie*fração; e $\varepsilon_{i j k}=$ erro.

Com relação ao controle de inibição de germinação e alongamento do hipocótilo e da radícula, em cada um dos extratos das frações das espécies esses valores foram classificados em: efetivos - limites superiores do intervalo de confiança de $95 \%$ da média iguais ou superiores a $50 \%$ de inibição; e potenciais - limites superiores do intervalo de confiança de $95 \%$ da média iguais ou superiores a $35 \%$ de inibição.

A diferença entre as médias de inibição de germinação, formação do hipocótilo e de 
radículas entre as espécies receptoras, em cada um dos extratos das frações das espécies, foi testada via teste $t$. Nesse sentido, a especificidade de inibição de uma dada fração das espécies, com relação às espécies-modelo, foi considerada em função da diferença significativa entre seus valores médios, tendo sido classificada como: efetiva - diferença estatística altamente significativa $(\mathrm{p}<0,001)$; e potencial - diferença estatística significativa $(\mathrm{p}<0,05)$.

Ordenação multivariada, efetuada por meio de análise de componentes principais, (PCA, Principal Component Analysis), foi empregada, constituindo-se da inibição de germinação e do alongamento do hipocótilo e radículas nas espécies receptoras Mimosa pudica e Senna obtusifolia pelos extratos das frações das espécies avaliadas. A extração dos autovalores adotou a regra de Kaiser, e a extração dos autovetores assinalou os que apresentassem valores de $|\lambda| \geq 0,35$.

\section{RESULTADOS E DISCUSSÃO}

\section{Efeitos potencialmente alelopáticos sobre Mimosa pudica}

Globalmente, a inibição da germinação apresentou valores superiores das espécies Bauhinia guianensis $\left(\delta_{(\mathrm{g})}=67 \%\right)$ e Parkia pendula $\left(\delta_{(\mathrm{g})}=63 \%\right)$, enquanto os menores valores foram assinalados em Swartzia multijuga $\left(\delta_{(\mathrm{g})}=28 \%\right)$, Dialinum guianensis $\left(\delta_{(\mathrm{g})}=22 \%\right)$ e Inga edulis $\left(\delta_{(\mathrm{g})}=16 \%\right)$. As espécies Bauhinia macrostachya, Bowdichia virgiloides e Platimenia reticulata $\left(\delta_{(g)}=48-56 \%\right)$ apresentaram valores intermediários. No tocante às frações da planta, as folhas $\left(\delta_{(\mathrm{g})}=48 \%\right)$ apresentaram valores superiores aos das raízes $\left(\delta_{(\mathrm{g})}=40 \%\right.$ ) (Tabela 1$)$. A fração raiz tendeu a apresentar menor atividade potencialmente alelopática, com valor superior somente nas espécies Inga edulis $\left(\delta_{(\mathrm{g})}=21 \%\right)$ e Bauhinia macrostachya $\left(\delta_{(\mathrm{g})}=58 \%\right)$. Quanto às demais espécies estudadas, a atividade alelopática inibitória da germinação foi superior sempre na fração folha (Tabela 1 e Figura 1A).

Na fração folha, as espécies Bauhinia guianensis $\left(\delta_{(\mathrm{g})}=80 \%\right)$ e Parkia pendula $\left(\delta_{(\mathrm{g})}=73 \%\right)$ mostraram os maiores valores de inibição da germinação, ao passo que Swartzia multijuga $\left(\delta_{(g)}=31 \%\right)$, Dialinum guianensis $\left(\delta_{(\mathrm{g})}=25 \%\right)$ e Inga edulis $\left(\delta_{(\mathrm{g})}=11 \%\right)$ apresentaram os menores valores de inibição. As outras espécies (Bowdichia virgiloides, Platimenia reticulata e Bauhinia macrostachya) apresentaram valores intermediários, porém sempre acima dos $50 \%$ (Tabela 1 e Figura 1A). Na fração raiz, os maiores valores de inibição foram registrados nas espécies Bauhinia macrostachya $\left(\delta_{(\mathrm{g})}=58 \%\right)$, Bauhinia guianensis $\left(\delta_{(\mathrm{g})}=54 \%\right)$ e Parkia pendula $\left(\delta_{(\mathrm{g})}=54 \%\right)$. Os menores valores de germinação foram assinalados em Swartzia multijuga $\left(\delta_{(\mathrm{g})}=25 \%\right)$, Inga edulis $\left(\delta_{(\mathrm{g})}=21 \%\right)$ e Dialinum guianensis $\left(\delta_{(\mathrm{g})}=18 \%\right)$. As espécies Bowdichia virgiloides $(\underset{(\mathrm{g})}{\mathrm{g})}=45 \%)$ e Platimenia reticulata $\left(\delta_{(\mathrm{g})}=42 \%\right)$ mostraram valores intermediários de inibição de germinação (Tabela 1 e Figura 1A).

As espécies apresentaram diferentes amplitudes de variação na atividade inibitória das frações folha e raizes. Para as espécies que mostraram maior atividade nas folhas, a maior diferença foi observada em Bauhinia guianensis - superioridade das folhas em 31\%. A fração folha de Dialinum guianensis e a de Parkia pendula apresentaram superioridade inibitória da ordem de $28 \%$ e $27 \%$, respectivamente, enquanto para Bowdichia virgiloides, Platimenia reticulata e Swartzia multijuga a superioridade variou de $22 \%$ a $23 \%$ (Tabela 1 ). Nas duas espécies em que a fração raiz foi mais efetiva, Inga edulis foi aquela com maior diferença entre as duas frações: $48 \%$ (Tabela 1).

A inibição do alongamento do hipocótilo apresentou, de modo global, maiores valores em Parkia pendula $\left(\delta_{(\mathrm{h})}=48 \%\right)$ e Bauhinia macrostachya $\left(\delta_{(\mathrm{h})}=47 \%\right)$ e valores intermediários em Platimenia reticulata $\left(\delta_{(\mathrm{h})}=43 \%\right)$, Bauhinia guianensis $\left(\delta_{(\mathrm{h})}=41 \%\right)$ e Bowdichia virgiloides $\left(\delta_{(\mathrm{h})}=38 \%\right)$. Os menores valores de inibição do alongamento do hipocótilo foram assinalados em Swartzia multijuga $\left(\delta_{(\mathrm{h})}=20 \%\right)$, Dialinum guianensis $\left(\delta_{(\mathrm{h})}=14 \%\right)$ e Inga edulis $\left(\delta_{(\mathrm{h})}=09 \%\right)$. Com relação ao fator frações da planta, a fração folha $\left(\delta_{(\mathrm{h})}=34 \%\right)$ foi superior $(\mathrm{p}<0,05)$ à fração raiz $\left(\delta_{(\mathrm{h})}=31 \%\right)$, embora a amplitude de variação tenha sido pequena (Tabela 1). Somente Parkia pendula $\left(\delta_{(\mathrm{h})}=48 \%\right)$ apresentou atividade alelopática inibitória equivalente entre as suas frações. Entre as espécies Bauhinia macrostachya $\left(\delta_{(\mathrm{h})}=50 \% ; 45 \%\right)$ e Inga edulis $\left(\delta_{(\mathrm{h})}=12 \% ; 5 \%\right)$, a fração raiz 
Tabela 1 - Valores médios e desvio-padrão de inibição de germinação $\left(\delta_{(\mathrm{g})}\right)$ e do alongamento do hipocótilo $\left(\delta_{(\mathrm{h})}\right)$ e da radícula $\left(\delta_{(\mathrm{r})}\right)$ de Mimosa pudica, em função dos extratos das frações de espécies de leguminosas, ordenados segundo o teste de Tukey $(\alpha=0,05)$. Dados expressos em percentual de inibição em relação ao tratamento testemunha-água destilada

\begin{tabular}{|c|c|c|c|c|}
\hline \multirow{2}{*}{ Bioensaio } & \multirow{2}{*}{ Espécie } & \multicolumn{2}{|c|}{ Fração } & \multirow{2}{*}{ Global } \\
\hline & & Folhas & Raízes & \\
\hline \multirow{9}{*}{$\delta_{(\mathrm{g})}$} & Bauhinia guianensis & $80,3 \pm 1,5 \mathrm{Aa}$ & $54,0 \pm 7,8 \mathrm{Ba}$ & $67,2 \pm 15,3 \mathrm{a}$ \\
\hline & Bauhinia macrostachya & $53,7 \pm 1,5 \mathrm{Bc}$ & $58,0 \pm 2,1 \mathrm{Aa}$ & $55,8 \pm 2,9 b$ \\
\hline & Bowdichia virgiloides & $58,3 \pm 1,5 \mathrm{Ac}$ & $45,0 \pm 1,5 \mathrm{Bb}$ & $51,7 \pm 7,4 \mathrm{bc}$ \\
\hline & Dialinum guianensis & $25,3 \pm 0,6 \mathrm{Ad}$ & $18,0 \pm 1,3 \mathrm{Bc}$ & $21,7 \pm 4,1 \mathrm{e}$ \\
\hline & Inga edulis & $11,3 \pm 1,2 \mathrm{Be}$ & $21,0 \pm 1,4 \mathrm{Ac}$ & $16,2 \pm 5,4 \mathrm{f}$ \\
\hline & Parkia pendula & $72,7 \pm 2,5 \mathrm{Ab}$ & $53,7 \pm 0,6 \mathrm{Ba}$ & $63,2 \pm 10,5 \mathrm{a}$ \\
\hline & Platimenia reticulata & $54,3 \pm 0,6 \mathrm{Ac}$ & $42,3 \pm 1,5 \mathrm{Bb}$ & $48,3 \pm 6,7 \mathrm{c}$ \\
\hline & Swartzia multijuga & $30,7 \pm 3,2 \mathrm{Ad}$ & $24,5 \pm 0,7 \mathrm{Bc}$ & $28,2 \pm 4,1 \mathrm{~d}$ \\
\hline & Global & $48,3 \pm 22,9 \mathrm{~A}$ & $40,2 \pm 15,6 \mathrm{~B}$ & $44,4 \pm 19,9$ \\
\hline \multirow{9}{*}{$\delta_{(\mathrm{h})}$} & Bauhinia guianensis & $45,3 \pm 1,5 \mathrm{Aab}$ & $36,0 \pm 1,4 \mathrm{Bb}$ & $40,7 \pm 5,2 b c$ \\
\hline & Bauhinia macrostachya & $44,7 \pm 0,6 \mathrm{Bab}$ & $50,0 \pm 1,3 \mathrm{Aa}$ & $47,3 \pm 3,2 \mathrm{a}$ \\
\hline & Bowdichia virgiloides & $42,3 \pm 1,5 \mathrm{Ac}$ & $33,3 \pm 1,5 \mathrm{Bb}$ & $37,8 \pm 5,1 \mathrm{c}$ \\
\hline & Dialinum guianensis & $16,3 \pm 2,1 \mathrm{Ae}$ & $11,0 \pm 1,5 \mathrm{Bd}$ & $13,7 \pm 3,3 \mathrm{e}$ \\
\hline & Inga edulis & $5,3 \pm 0,6 \mathrm{Bf}$ & $11,7 \pm 1,5 \mathrm{Acd}$ & $8,5 \pm 3,6 f$ \\
\hline & Parkia pendula & $48,3 \pm 1,5 \mathrm{Aa}$ & $47,7 \pm 1,5 \mathrm{Aa}$ & $48,0 \pm 1,4 \mathrm{a}$ \\
\hline & Platimenia reticulata & $48,0 \pm 2,6 \mathrm{Aa}$ & $37,7 \pm 0,6 \mathrm{Bb}$ & $42,8 \pm 5,9 b$ \\
\hline & Swartzia multijuga & $22,0 \pm 4,4 \mathrm{Ad}$ & $16,0 \pm 0,9 \mathrm{Bc}$ & $19,6 \pm 4,5 \mathrm{~d}$ \\
\hline & Global & $34,0 \pm 16,2 \mathrm{~A}$ & $31,0 \pm 15 \mathrm{~B}$ & $32,6 \pm 15,5$ \\
\hline \multirow{9}{*}{$\delta_{(\mathrm{r})}$} & Bauhinia guianensis & $88,7 \pm 1,5 \mathrm{Aa}$ & $75,3 \pm 1,5 \mathrm{Ba}$ & $82,0 \pm 7,4 \mathrm{a}$ \\
\hline & Bauhinia macrostachya & $60,7 \pm 2,1 \mathrm{Bb}$ & $69,0 \pm 1,4 \mathrm{Aa}$ & $64,8 \pm 4,8 \mathrm{~b}$ \\
\hline & Bowdichia virgiloides & $59,7 \pm 1,5 \mathrm{Ab}$ & $53,3 \pm 1,5 \mathrm{Bb}$ & $56,5 \pm 3,7 \mathrm{c}$ \\
\hline & Dialinum huianensis & $34,0 \pm 1,5 \mathrm{Ad}$ & $27,3 \pm 1,5 \mathrm{Bd}$ & $30,7 \pm 3,8 \mathrm{e}$ \\
\hline & Inga edulis & $26,3 \pm 1,5 \mathrm{Be}$ & $35,3 \pm 2,1 \mathrm{Ac}$ & $30,8 \pm 5,2 \mathrm{e}$ \\
\hline & Parkia pendula & $57,7 \pm 2,1 \mathrm{Ab}$ & $48,3 \pm 1,5 \mathrm{Bb}$ & $53,0 \pm 5,4 \mathrm{c}$ \\
\hline & Platimenia reticulata & $58,0 \pm 2,3 \mathrm{Ab}$ & $54,7 \pm 0,6 \mathrm{Ab}$ & $56,3 \pm 2,3 \mathrm{c}$ \\
\hline & Swartzia multijuga & $41,3 \pm 7,4 \mathrm{Ac}$ & $34 \pm 2,8 \mathrm{Bcd}$ & $38,4 \pm 6,7 \mathrm{~d}$ \\
\hline & Global & $53,3 \pm 18,7 \mathrm{~A}$ & $50,3 \pm 16,3 \mathrm{~B}$ & $51,9 \pm 17,4$ \\
\hline
\end{tabular}

Médias seguidas de letras iguais, maiúsculas na linha e minúsculas na coluna, não diferem significativamente pelo teste de Tukey a $5 \%$.

apresentou valores de inibição superiores aos das folhas.

A relação entre espécies doadoras e frações da planta indica tendência de as folhas serem mais ativas do que as raízes em se tratando de inibições do alongamento do hipocótilo, à exceção dos efeitos promovidos pelas espécies Bauhinia macrostachya e Inga edulis, cujos efeitos potencialmente alelopáticos inibitórios foram mais intensos na fração raiz do que nas folhas (Tabela 1 e Figura 1B). Especificamente em relação aos efeitos promovidos por Parkia pendula, não foi observada diferença estatística $(\mathrm{P}>0,05)$ entre as inibições promovidas pelas folhas e raizes, embora quantitativamente a inibição promovida pela fração folha tenha sido ligeiramente superior (Tabela $1 \mathrm{e}$ Figura 1B). Comparativamente, as espécies Dialinum guianensis e Swartzia multijuga foram as que apresentaram maior amplitude de variação entre os efeitos inibitórios promovidos sobre o alongamento do hipocótilo de Mimosa pudica, com superioridade de $31 \%$ e $27 \%$ em prol da fração folha, respectivamente para as duas espécies. Amplitude de 20\% de 
variação foi observada para a diferença entre os efeitos alelopáticos de folha e raiz nas espécies Bauhinia guianensis, Bowdichia virgiloides e Platimenia reticulata. Para Bauhinia macrostachya e Inga edulis, que evidenciaram maior atividade inibitória nas raízes, as diferenças ficaram em $10 \%$ e $58 \%$, respectivamente (Tabela 1 ).

(A)

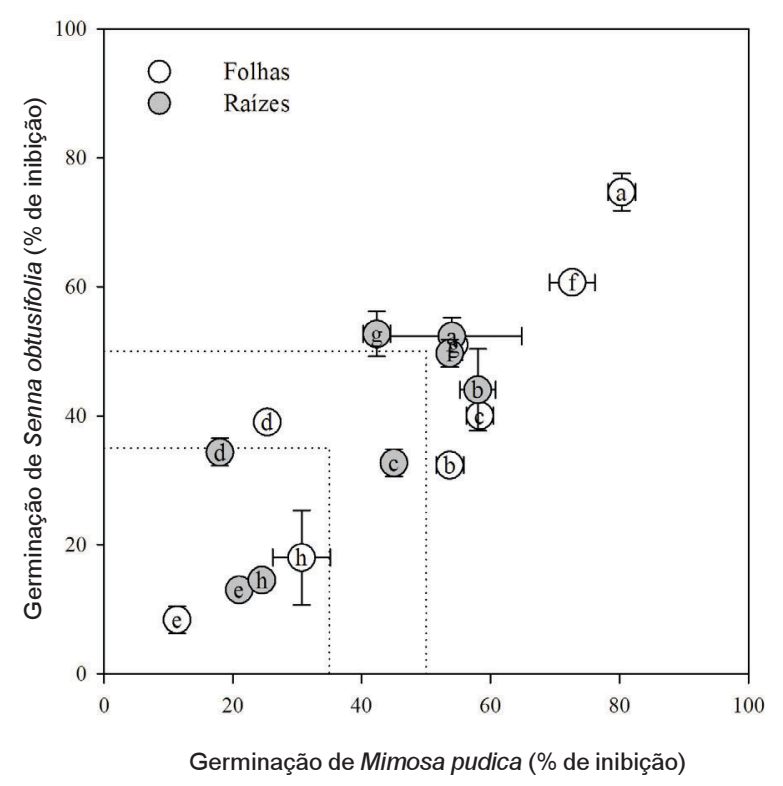

O alongamento radicular teve a sua inibição, de maneira geral, superiormente assinalada em Bauhinia guianensis $\left(\delta_{(\mathrm{r})}=82 \%\right)$; valores intermediários foram observados em Bauhinia macrostachya $\left(\delta_{(\mathrm{r})}=65 \%\right)$, Bowdichia virgiloides $\left(\delta_{(\mathrm{r})}=57 \%\right)$, Platimenia reticulata $\left(\delta_{(\mathrm{r})}=56 \%\right)$ e Parkia pendula $\left(\delta_{(\mathrm{r})}=53 \%\right)$. As espécies Swartzia multijuga $\left(\delta_{(\mathrm{r})}=38 \%\right)$, Inga edulis $\left(\delta_{(\mathrm{r})}=31 \%\right)$ e

(B)

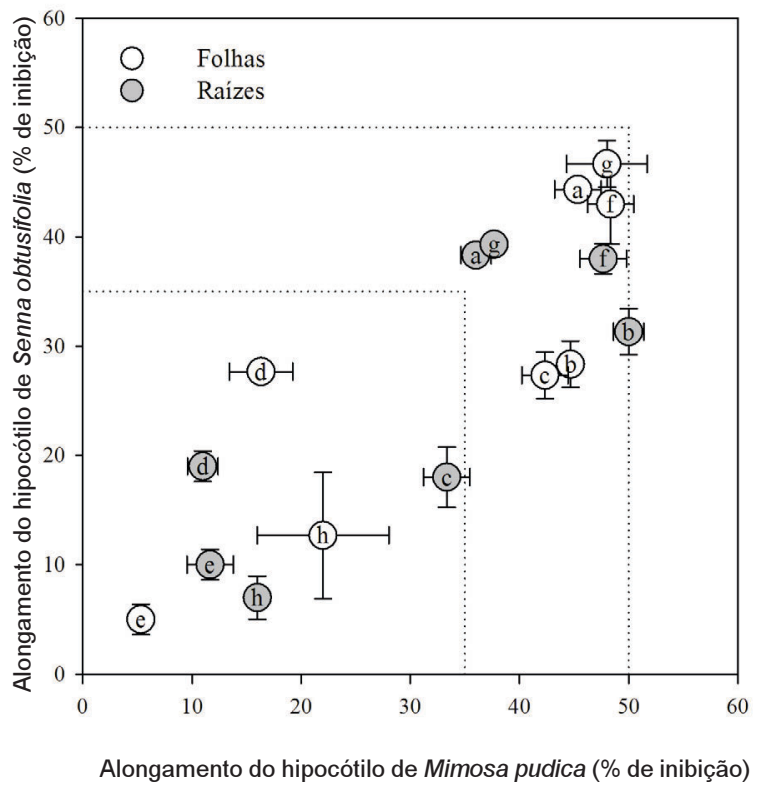

(C)

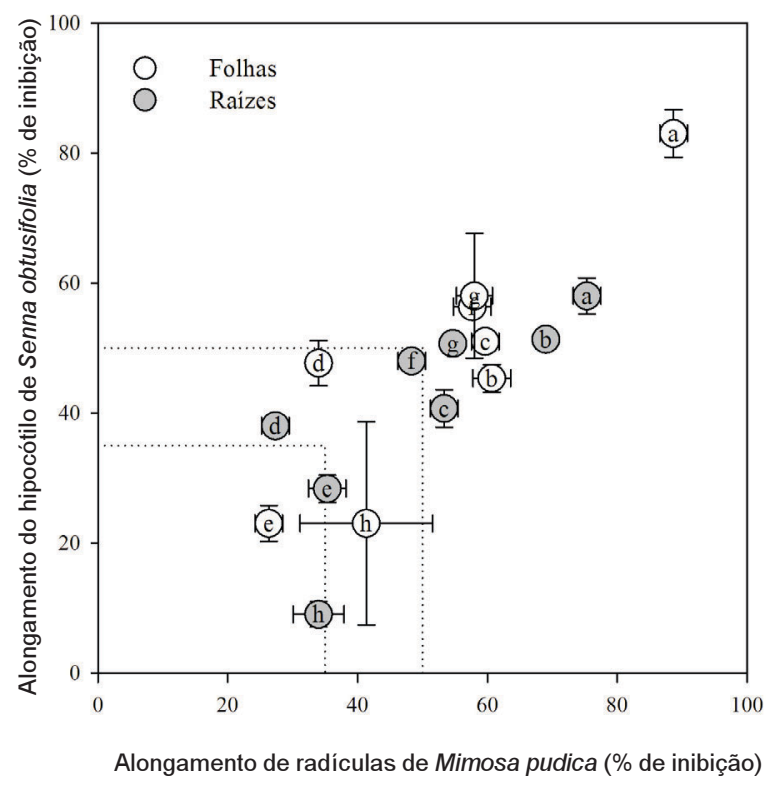

Figura 1 - Valores médios de inibição da (A) germinação e do (B) alongamento do hipocótilo e (C) radículas de Mimosa pudica e Senna obtusifolia, em função dos extratos de diferentes espécies de Leguminosae. 
Dialinum guianensis $\left(\delta_{(\mathrm{r})}=31 \%\right)$ mostraram valores inferiores de inibição do alongamento radicular. Globalmente, a fração folha $\left(\delta_{(\mathrm{r})}=53 \%\right)$ apresentou valores superiores ao da fração raiz $\left(\delta_{(\mathrm{r})}=50 \%\right)$ (Tabela 1$)$. Somente a espécie Platimenia reticulata $\left(\delta_{(\mathrm{r})}=55-58 \%\right)$ apresentou equivalência entre as suas frações. Bauhinia guianensis $\left(\delta_{(\mathrm{r})}=89 \% ; 75 \%\right)$, Bowdichia virgiloides $\left(\delta_{(\mathrm{r})}=60 \% ; 53 \%\right)$, Parkia pendula $\left(\delta_{(\mathrm{r})}=58 \% ; 48 \%\right)$, Swartzia multijuga $\left(\delta_{(\mathrm{r})}=41 \% ; 34 \%\right)$ e Dialinum guianensis $\left(\delta_{(\mathrm{r})}=34 \% ; 27 \%\right)$ apresentaram valores superiores de inibição do alongamento radicular na fração folha. Bauhinia macrostachya $\left(\delta_{(\mathrm{r})}=69 \% ; 61 \%\right)$ e Inga edulis $\left(\delta_{(r)}=35 \% ; 26 \%\right)$ mostraram maior inibição na fração raiz (Tabela 1 e Figura 1C).

A diferença na intensidade dos efeitos alelopáticos inibitórios promovidos pelas duas frações das plantas sobre o alongamento da radícula variou na amplitude de $10 \%$ até $21 \%$. A maior diferença foi obtida em Dialinum guianensis, que atingiu $21 \%$, ficando Parkia pendula e Swartzia multijuga com $17 \%$. A menor diferença entre os efeitos promovidos pelas frações folha e raiz foi observada em Platimenia reticulata, com apenas $7,0 \%$. As diferenças nas intensidades dos efeitos promovidos pelas frações folha e raízes em Bauhinia macrostachya e Inga edulis foram de 13\% e 26\%, em prol das raízes (Tabela 1 ).

\section{Efeitos potencialmente alelopáticos sobre Senna obtusifolia}

A inibição da germinação, de maneira global, em Senna obtusifolia apresentou valores superiores em Bauhinia guianensis $\left(\delta_{(\mathrm{g})}=64 \%\right)$, Parkia pendula $\left(\delta_{(\mathrm{g})}=64 \%\right)$ e Platimenia reticulata $\left(\delta_{(\mathrm{g})}=64 \%\right)$ e valores inferiores em Swartzia multijuga $\left(\delta_{(\mathrm{g})}=17 \%\right)$ e Inga sp. $\left(\delta_{(\mathrm{g})}=11 \%\right)$. As espécies Bauhinia macrostachya $\left(\delta_{(\mathrm{g})}=38 \%\right)$, Dialinum guianensis $\left(\delta_{(\mathrm{g})}=37 \%\right)$ e Bowdichia virgiloides $\left(\delta_{(\mathrm{g})}=36 \%\right)$ mostraram valores intermediários. Também de maneira global, foi possivel determinar maiores valores de inibição da germinação na fração folha $\left(\delta_{(\mathrm{g})}=41 \%\right)$ quando comparada à fração raiz $\left(\delta_{(\mathrm{g})}=38 \%\right)$ (Tabela 2).

As frações de planta foram equivalentes nas espécies Platimenia reticulata $\left(\delta_{(\mathrm{g})}=51-53 \%\right)$ e Swartzia multijuga $\left(\delta_{(\mathrm{g})}=15-18 \%\right)$. Nas espécies Bauhinia macrostachya $\left(\delta_{(\mathrm{g})}=44 \% ; 32 \%\right)$ e
Inga edulis $\left(\delta_{(g)}=13 \%\right.$; 08\%), a fração raiz foi superior à fração folha (Tabela 2). No caso das espécies Bauhinia guianensis $\left(\delta_{(\mathrm{g})}=75 \% ; 52 \%\right)$, Parkia pendula $\left(\delta_{(\mathrm{g})}=61 \% ; 50 \%\right)$, Bowdichia virgiloides $\left(\delta_{(\mathrm{g})}=40 \% ; 33 \%\right)$ e Dialinum guianensis $\left(\delta_{(\mathrm{g})}=39 \% ; 34 \%\right)$, houve maior inibição de germinação na fração folha em relação a fração raiz (Tabela 2 e Figura 1A). Na fração folha, os maiores valores de inibição foram assinalados em Bauhinia guianensis $\left(\delta_{(\mathrm{g})}=75 \%\right)$, Parkia pendula $\left(\delta_{(\mathrm{g})}=61 \%\right)$ e Platimenia reticulata $\left(\delta_{(\mathrm{g})}=51 \%\right)$, enquanto os menores valores foram assinalados em Swartzia multijuga $\left(\delta_{(\mathrm{g})}=18 \%\right)$ e Inga edulis $\left(\delta_{(\mathrm{g})}=08 \%\right)$. As outras espécies apresentaram valores intermediários $\left(\delta_{(\mathrm{g})}=32-40 \%\right)$ (Tabela 2 e Figura 1A).

$\mathrm{Na}$ fração raiz, os maiores valores de inibição da germinação foram assinalados em Platimenia reticulata $\left(\delta_{(\mathrm{g})}=53 \%\right)$, Bauhinia guianensis $\left(\delta_{(\mathrm{g})}=52 \%\right)$, Parkia pendula $\left(\delta_{(\mathrm{g})}=50 \%\right)$ e Bauhinia macrostachya $\left(\delta_{(\mathrm{g})}=44 \%\right)$. Os menores valores de inibição também foram assinalados nas espécies Swartzia multijuga $\left(\delta_{(\mathrm{g})}=15 \%\right)$ e Inga edulis $\left(\delta_{(\mathrm{g})}=13 \%\right)$. Dialinum guianensis $\left(\delta_{(\mathrm{g})}=34 \%\right)$ e Bowdichia virgiloides $\left(\delta_{(\mathrm{g})}=33 \%\right)$ apresentaram valores intermediários de inibição da germinação de Senna obtusifolia (Tabela 2 e Figura 1A).

As diferenças entre os efeitos alelopáticos inibitórios da germinação, promovidas pelas duas frações das plantas, apresentaram ampla variação: de no mínimo $13 \%$ até $30 \%$. A maior variação na diferença entre a atividade de folhas e a de raizes foi observada para Bauhinia guianensis, com superioridade para as folhas de 30\%. Em Swartzia multijuga, Bowdichia virgiloides e Parkia pendula a atividade da fração folha foi $22 \%$, $18 \%$ e $17 \%$ superior àquela efetivada pelas raízes, respectivamente para as três espécies. Para Bauhinia macrostachya e Inga edulis, a atividade alelopática nas raízes foi $27 \%$ e $38 \%$ superior à da fração folha, respectivamente (Tabela 2).

A inibição do alongamento do hipocótilo apresentou, de modo geral, maiores valores em Platimenia reticulata $\left(\delta_{(\mathrm{h})}=43 \%\right)$, Bauhinia guianensis $\left(\delta_{(\mathrm{h})}=41 \%\right)$ e Parkia pendula $\left(\delta_{(\mathrm{h})}=41 \%\right)$; os menores valores foram assinalados em Swartzia multijuga $\left(\delta_{(\mathrm{h})}=10 \%\right)$ e Inga edulis $\left(\delta_{(\mathrm{h})}=08 \%\right)$. As espécies Bauhinia macrostachya $\left(\delta_{(\mathrm{h})}=30 \%\right)$, Dialinum guianensis $\left(\delta_{(\mathrm{h})}=23 \%\right)$ e Bowdichia virgiloides $\left(\delta_{(\mathrm{h})}=23 \%\right)$ mostraram valores intermediários (Tabela 2). 
Tabela 2 - Valores médios e desvio-padrão de inibição de germinação $\left(\delta_{(\mathrm{g})}\right)$ e do alongamento do hipocótilo $\left(\delta_{(\mathrm{h})}\right)$ e da radícula $\left(\delta_{(\mathrm{r})}\right)$ de Senna obtusifolia, em função dos extratos das rações de espécies de Leguminosas, ordenados segundo o teste de Tukey $(\alpha=0,05)$ Dados expressos em percentual de inibição em relação ao tratamento testemunha - água destilada

\begin{tabular}{|c|c|c|c|c|}
\hline \multirow{2}{*}{ Bioensaio } & \multirow{2}{*}{ Espécie } & \multicolumn{2}{|c|}{ Fração } & \multirow{2}{*}{ Global } \\
\hline & & Folhas & Raízes & \\
\hline \multirow{9}{*}{$\delta_{(\mathrm{g})}$} & Bauhinia guianensis & $74,7 \pm 2,1 \mathrm{Aa}$ & $52,3 \pm 2,1 \mathrm{Ba}$ & $63,5 \pm 12,4 \mathrm{a}$ \\
\hline & Bauhinia macrostachya & $32,3 \pm 0,6 \mathrm{Be}$ & $44,0 \pm 4,6 \mathrm{Ab}$ & $38,2 \pm 7,1 \mathrm{c}$ \\
\hline & Bowdichia virgiloides & $40,0 \pm 1,4 \mathrm{Ad}$ & $32,7 \pm 1,5 \mathrm{Bc}$ & $36,3 \pm 4,2 \mathrm{c}$ \\
\hline & Dialinum guianensis & $39,0 \pm 1,5 \mathrm{Ad}$ & $34,3 \pm 1,5 \mathrm{Bc}$ & $36,7 \pm 2,8 \mathrm{c}$ \\
\hline & Inga edulis & $8,3 \pm 1,5 \mathrm{Bg}$ & $13,0 \pm 1,3 \mathrm{Ad}$ & $10,7 \pm 2,8 \mathrm{e}$ \\
\hline & Parkia pendula & $60,7 \pm 1,2 \mathrm{Ab}$ & $49,7 \pm 1,5 \mathrm{Bab}$ & $55,2 \pm 6,1 \mathrm{~b}$ \\
\hline & Platimenia reticulata & $51,0 \pm 1,7 \mathrm{Ac}$ & $52,7 \pm 2,5 \mathrm{Aa}$ & $51,8 \pm 2,1 \mathrm{~b}$ \\
\hline & Swartzia multijuga & $18,0 \pm 5,3 \mathrm{Af}$ & $14,5 \pm 0,7 \mathrm{Ad}$ & $16,6 \pm 4,2 d$ \\
\hline & Global & $40,5 \pm 20,8 \mathrm{~A}$ & $37,6 \pm 15 \mathrm{~B}$ & $39,1 \pm 18,1$ \\
\hline \multirow{9}{*}{$\delta_{(\mathrm{h})}$} & Bauhinia guianensis & $44,3 \pm 0,6 \mathrm{Aa}$ & $38,3 \pm 0,6 \mathrm{Ba}$ & $41,3 \pm 3,3 \mathrm{a}$ \\
\hline & Bauhinia macrostachya & $28,3 \pm 1,5 \mathrm{Bb}$ & $31,3 \pm 1,5 \mathrm{Ab}$ & $29,8 \pm 2,1 \mathrm{~b}$ \\
\hline & Bowdichia virgiloides & $27,3 \pm 1,5 \mathrm{Ab}$ & $18 \pm 2,4 \mathrm{Bc}$ & $22,7 \pm 5,4 c$ \\
\hline & Dialinum guianensis & $27,7 \pm 0,6 \mathrm{Ab}$ & $19,0 \pm 1,3 \mathrm{Bc}$ & $23,3 \pm 4,8 \mathrm{c}$ \\
\hline & Inga edulis & $5,0 \pm 1,5 \mathrm{Bd}$ & $10,0 \pm 1,2 \mathrm{Ad}$ & $7,5 \pm 2,9 \mathrm{~d}$ \\
\hline & Parkia pendula & $43,0 \pm 2,6 \mathrm{Aa}$ & $38,0 \pm 1,3 \mathrm{Ba}$ & $40,5 \pm 3,3 \mathrm{a}$ \\
\hline & Platimenia reticulata & $46,7 \pm 1,5 \mathrm{Aa}$ & $39,3 \pm 0,6 \mathrm{Ba}$ & $43,0 \pm 4,1 \mathrm{a}$ \\
\hline & Swartzia multijuga & $12,7 \pm 4,2 \mathrm{Ac}$ & $7,0 \pm 1,4 \mathrm{Bd}$ & $10,4 \pm 4,3 d$ \\
\hline & Global & $29,4 \pm 14,5 \mathrm{~A}$ & $25,9 \pm 12,4 \mathrm{~B}$ & $27,7 \pm 13,5$ \\
\hline \multirow{9}{*}{$\delta_{(\mathrm{r})}$} & Bauhinia guianensis & $83,0 \pm 2,6 \mathrm{Aa}$ & $58,0 \pm 2 \mathrm{Ba}$ & $70,5 \pm 13,9 a$ \\
\hline & Bauhinia macrostachya & $45,3 \pm 1,5 \mathrm{Ad}$ & $51,3 \pm 1,2 \mathrm{Aa}$ & $48,3 \pm 3,5 \mathrm{bcd}$ \\
\hline & Bowdichia virgiloides & $51,0 \pm 1,2 \mathrm{Abcd}$ & $40,7 \pm 2,1 \mathrm{Bbc}$ & $45,8 \pm 5,8 \mathrm{~cd}$ \\
\hline & Dialinum guianensis & $47,7 \pm 2,5$ Acd & $38,0 \pm 1,3 \mathrm{Bcd}$ & $42,8 \pm 5,6 \mathrm{~d}$ \\
\hline & Inga edulis & $23,0 \pm 2,2 \mathrm{Ae}$ & $28,3 \pm 1,5 \mathrm{Ad}$ & $25,7 \pm 3,3 \mathrm{e}$ \\
\hline & Parkia pendula & $56,3 \pm 0,6 \mathrm{Abc}$ & $48,0 \pm 1,3 \mathrm{Babc}$ & $52,2 \pm 4,6 \mathrm{bc}$ \\
\hline & Platimenia reticulata & $58,0 \pm 6,9 \mathrm{Ab}$ & $50,7 \pm 0,6 \mathrm{Bab}$ & $54,3 \pm 6,1 \mathrm{~b}$ \\
\hline & Swartzia multijuga & $23,0 \pm 11,3 \mathrm{Ae}$ & $9,0 \pm 1,4,1 \mathrm{Be}$ & $17,4 \pm 11,1 \mathrm{f}$ \\
\hline & Global & $48,4 \pm 19,1 \mathrm{~A}$ & $41,9 \pm 13,8 \mathrm{~B}$ & $45,2 \pm 16,8$ \\
\hline
\end{tabular}

Médias seguidas de letras iguais, maiúsculas na linha e minúsculas na coluna, não diferem significativamente segundo o teste de Tukey, no nível de $5 \%$.

Nenhuma das espécies apresentou equivalência entre as frações da planta; somente Bauhinia macrostachya $\left(\delta_{(\mathrm{h})}=31 \% ; 28 \%\right)$ e Inga edulis $\left(\delta_{(\mathrm{h})}=10 \%\right.$; 05\%) mostraram valores superiores na fração raiz. Platimenia reticulata $\left(\delta_{(\mathrm{h})}=47 \% ; 39 \%\right)$, Bauhinia guianensis $\left(\delta_{(\mathrm{h})}=44 \%\right.$; $38 \%)$, Parkia pendula $\left(\delta_{(\mathrm{h})}=43 \% ; 38 \%\right)$, Dialinum guianensis $\left({ }_{(\mathrm{h})}=28 \% ; 19 \%\right)$, Bowdichia virgiloides $\left(\delta_{(\mathrm{h})}=27 \% ; 18 \%\right)$ e Swartzia multijuga $\left(\delta_{(\mathrm{h})}=13 \%\right.$; $7 \%$ ) apresentaram valores superiores na fração folha (Tabela 2).
Na fração folha, as espécies Platimenia reticulata $\left(\delta_{(\mathrm{h})}=47 \%\right)$, Bauhinia guianensis $\left(\delta_{(\mathrm{h})}=44 \%\right)$ e Parkia pendula $\left(\delta_{(\mathrm{h})}=43 \%\right)$ apresentaram valores superiores, e Swartzia multijuga $\left(\delta_{(\mathrm{h})}=12,7 \%\right)$ e Inga edulis $\left(\delta_{(\mathrm{h})}=5,0 \%\right)$, valores inferiores de inibição do alongamento do hipocótilo em Senna obtusifolia. As espécies Bauhinia macrostachya $\left(\delta_{(\mathrm{h})}=28 \%\right)$, Dialinum guianensis $\left(\delta_{(\mathrm{h})}=28 \%\right)$ e Bowdichia virgiloides $\left(\delta_{(\mathrm{h})}=27 \%\right)$ tiveram valores intermediários de inibição (Tabela 2 e Figura 1B). Na fração raiz, 
Platimenia reticulata $\left(\delta_{(\mathrm{h})}=39 \%\right)$, Bauhinia guianensis $\left(\delta_{(\mathrm{h})}=38 \%\right)$ e Parkia pendula $\left(\delta_{(\mathrm{h})}=38 \%\right)$ mostraram os maiores valores de inibição do alongamento do hipocótilo, Inga edulis $\left(\delta_{(\mathrm{h})}=10 \%\right)$ e Swartzia multijuga $\left(\delta_{(\mathrm{h})}=7 \%\right)$, os menores valores de inibição. As espécies Bauhinia macrostachya $\left(\delta_{(\mathrm{h})}=31 \%\right)$, Dialinum guianensis $\left(\delta_{(\mathrm{h})}=19 \%\right)$ e Bowdichia virgiloides $\left(\delta_{(\mathrm{h})}=18 \%\right)$ apresentaram valores intermediários (Tabela 2 e Figura 1B).

A magnitude da diferença na intensidade dos efeitos alelopáticos efetivados pelas frações folha e raiz variou no intervalo de $12 \%$ a $42 \%$ entre as espécies Parkia pendula e Swartzia multijuga, respectivamente. Em Bowdichia virgiloides e Dialinum guianensis, as diferenças nas intensidades foram entre $33 \%$ e $32 \%$, respectivamente. Considerando os efeitos promovidos por Bauhinia macrostachya e Inga edulis, as diferenças foram de $10 \%$ a $50 \%$, em favor das raízes (Tabela 2).

A inibição do alongamento radicular, de modo geral, foi superior em Bauhinia guianensis $\left(\delta_{(\mathrm{r})}=71 \%\right)$ e inferior em Inga edulis $\left(\delta_{(\mathrm{r})}=26 \%\right)$ e Swartzia multijuga $\left(\delta_{(\mathrm{r})}=17 \%\right)$. As espécies Platimenia reticulata $\left({ }_{(\mathrm{r})}=54 \%\right)$, Parkia pendula $\left(\delta_{(\mathrm{r})}=52 \%\right)$, Bauhinia macrostachya $\left(\delta_{(\mathrm{r})}=48 \%\right)$, Bowdichia virgiloides $\left(\delta_{(\mathrm{r})}=46 \%\right)$ e Dialinum guianensis $\left(\delta_{(\mathrm{r})}=43 \%\right)$ apresentaram valores intermediários. Também de maneira global, a fração folha $\left(\delta_{(r)}=48 \%\right)$ foi superior à fração raiz $\left(\delta_{(\mathrm{r})}=42 \%\right)$ (Tabela 2).

Entre as espécies, somente Bauhinia macrostachya $\left(\delta_{(\mathrm{r})}=45-51 \%\right)$ e Inga edulis $\left(\delta_{(\mathrm{r})}=23-\right.$ $28 \%)$ mostraram equivalência entre as frações. Bauhinia guianensis $\left(\delta_{(\mathrm{r})}=83 \% ; 58 \%\right)$, Bowdichia virgiloides $\left(\delta_{(\mathrm{r})}=51 \% ; 41 \%\right)$, Dialinum guianensis $\left(\delta_{(\mathrm{r})}=48 \% ; 38 \%\right)$, Parkia pendula $\left(\delta_{(\mathrm{r})}=56 \% ; 48 \%\right)$, Platimenia reticulata $\left(\delta_{(\mathrm{r})}=58 \%\right.$; $50 \%)$ e Swartzia multijuga $\left(\delta_{(\mathrm{r})}=23 \%\right.$; 09\%) apresentaram valores superiores na fração folha (Tabela 2). Nesta fração, a espécie com inibição superior foi Bauhinia guianensis $\left(\delta_{(\mathrm{r})}=83 \%\right)$, enquanto Platimenia reticulata $\left(\delta_{(\mathrm{r})}=58 \%\right)$, Parkia pendula $\left(\delta_{(\mathrm{r})}=56 \%\right)$, Bowdichia virgiloides $\left(\delta_{(\mathrm{r})}=51 \%\right)$, Dialinum guianensis $\left(\delta_{(\mathrm{r})}=48 \%\right)$ e Bauhinia macrostachya $\left(\delta_{(\mathrm{r})}=45 \%\right)$ mostraram valores intermediários. As espécies Inga edulis $\left(\delta_{(\mathrm{r})}=23 \%\right)$ e Swartzia multijuga $\left(\delta_{(\mathrm{r})}=23 \%\right)$ apresentaram valores inferiores de inibição do alongamento das radículas de Senna obtusifolia (Tabela 2 e Figura 1C).
Na fração raiz, a espécie Swartzia multijuga $\left(\delta_{(r)}=09 \%\right)$ foi a que apresentou a menor inibição do alongamento das radículas, e Inga edulis $\left(\delta_{(\mathrm{r})}=28 \%\right)$, valores intermediários. Bauhinia guianensis $\left(\delta_{(\mathrm{r})}=58 \%\right)$, Bauhinia macrostachya $\left(\delta_{(\mathrm{r})}=51 \%\right)$, Platimenia reticulata $\left(\delta_{(\mathrm{r})}=51 \%\right)$, Parkia pendula $\left(\delta_{(\mathrm{r})}=48 \%\right)$, Bowdichia virgiloides $\left(\delta_{(\mathrm{r})}=41 \%\right)$ e Dialinum guianensis $\left(\delta_{(\mathrm{r})}=38 \%\right)$ mostraram valores superiores de inibição do alongamento radicular (Tabela 2 e Figura 1C).

A amplitude de variação na atividade alelopática das duas frações das plantas atingiu diferentes valores entre as espécies. Em Swartzia multijuga, a atividade alelopática das folhas foi $61 \%$ superior àquela observada nas raízes. Nas espécies Bauhinia guianensis e Bauhinia macrostachya, as folhas foram mais efetivas do que as raízes em $30 \%$ e $27 \%$, respectivamente. As menores amplitudes de variação foram observadas em Parkia pendula e Platimenia reticulata, com superioridade das folhas em apenas $14 \%$, para ambas as espécies. A superioridade das raízes, em relação às folhas, foi da ordem de $12 \%$ e $18 \%$ em Bauhinia macrostachya e Inga edulis, respectivamente (Tabela 2 ).

Quando se considera o efeito global promovido pelos extratos sobre a germinação e o alongamento da radícula e do hipocótilo (Tabelas 1 e 2), observa-se que o padrão dos efeitos tóxicos incidiu com maior intensidade na espécie Mimosa pudica, indicando maior especificidade e efetividade entre as espécies doadoras dos extratos e suas frações e essa planta receptora, conforme se pode observar na Tabela 4.

\section{ORDENAÇÃO DOS RESULTADOS}

A partir dos valores de inibição de germinação e alongamento do hipocótilo e das radículas nas espécies receptoras, foi efetuada análise multivariada de agrupamento, a qual assinalou três agrupamentos (Figura 2A): $\mathrm{G}_{(1)}$ $\sim$ Dialinum guianensis - ambas as frações, Inga edulis - ambas as frações, Swartzia multijugaambas as frações; $\mathrm{G}_{(2)} \sim$ Bauhinia macrostachya - ambas as frações, Bowdichia virgiloides ambas as frações, Parkia pendula - fração "raiz" e Platimenia reticulata - fração "raiz"; e $\mathrm{G}_{(3)}$ " Bauhinia guianensis - ambas as frações, Parkia pendula - fração "folha" e Platimenia reticulata - fração "folha". 
(A)

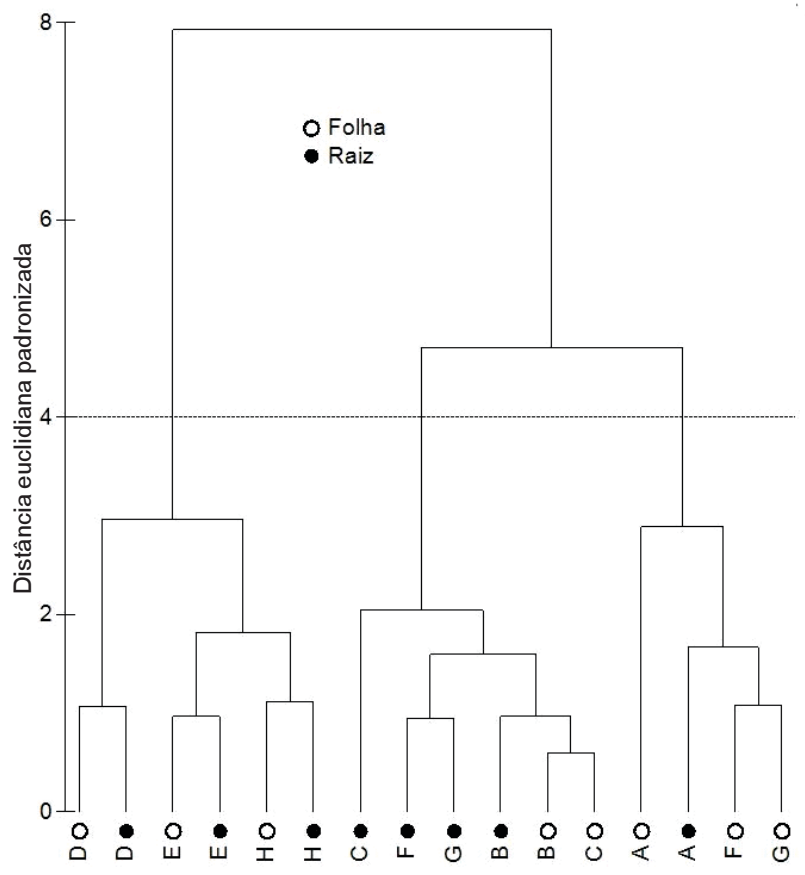

(B)

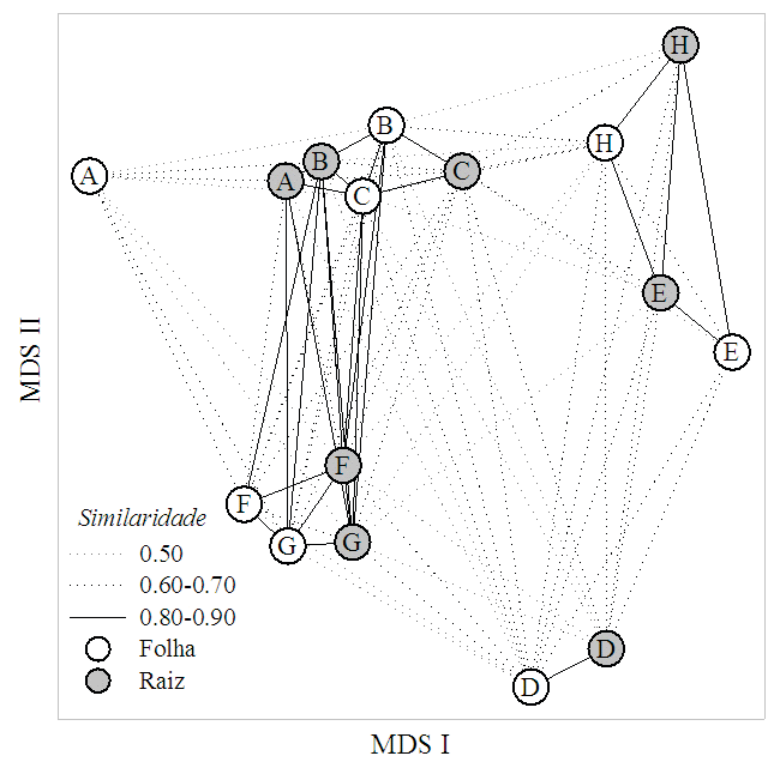

Figura 2 - (A) Dendrograma de dissimilaridade entre os extratos em função dos valores médios dos bioensaios e (B) topologia da afinidade dos extratos obtidos na análise multidimensional não métrica. A - Bauhinia guianensis; B - Bauhinia macrostachya; C - Bowdichia virgiloides; D - Dialinum guianensis; E - Inga edulis; F - Parkia pendula; G - Platimenia reticulata; H - Swartzia multijuga.

Globalmente, o $\mathrm{G}_{(1)}$ apresentou valores inferiores de inibição em todos os bioensaios, enquanto $G_{(3)}$ mostrou valores superiores em todos os bioensaios, à exceção da inibição do alongamento do hipocótilo, o qual foi muito próximo ao valor observado em $\mathrm{G}_{(2)}$. Ressaltando-se a exceção, descrita anteriormente, $\mathrm{G}_{(2)}$ apresentou valores intermediários em todos os bioensaios avaliados (Tabela 3).

Buscando estabelecer maior homogeneidade dentros dos grupos, foi efetuada uma análise multidimensional não métrica (NMDS, Non-metric multidimensional scalling), a qual estabeleceu uma nova estrutura de maior afinidade entre os extratos avaliados (Figura 2B), definindo os seguintes agrupamentos: $G_{(1 . a)} \sim$ Inga edulis-ambas as frações e Swartzia multijuga - ambas as frações; $\mathrm{G}_{(1 . b)} \sim$ Dialinum guianensis - ambas as frações; $\mathrm{G}_{\left(2^{\star}\right)} \sim$ Bauhinia macrostachya - ambas as frações, Bowdichia virgiloides ambas as frações, Parkia pendula - ambas as frações, Platimenia reticulata - ambas as frações e Bauhinia guianensis - fração "raiz"; e $\mathrm{G}_{\left(3^{\star}\right)}$ Bauhinia guianensis - fração folha.
A nova classificação apresentou as seguintes características: $G_{(1 . a)}$ - menores valores de inibição em todos os bioensaios; $G_{(1 . b)}$-valores equivalentes a $\mathrm{G}_{(1 . \mathrm{a})}$ nos bioensaios de Mimosa pudica e valores superiores nos bioensaios de Senna obtusifolia; $\mathrm{G}_{\left(2^{\star}\right)}$ - valores intermediários em todos os bioensaios, tanto de Mimosa pudica quanto de Senna obtusifolia, à exceção da inibição do alongamento do hipocótilo de Mimosa pudica, o qual apresentou valor próximo a $\mathrm{G}_{\left(3^{\star}\right)}$;

Tabela 3 - Valores médios dos bioensaios de inibição em função dos agrupamentos evidenciados

\begin{tabular}{|c|c|c|c|c|c|c|}
\hline \multirow{2}{*}{ Agrupamento } & \multicolumn{3}{|c|}{ Mimosa pudica } & \multicolumn{3}{c|}{ Senna obtusifolia } \\
\cline { 2 - 7 } & $\delta_{(\mathrm{g})}$ & $\delta_{(\mathrm{h})}$ & $\delta_{(\mathrm{r})}$ & $\delta_{(\mathrm{g})}$ & $\delta_{(\mathrm{h})}$ & $\delta_{(\mathrm{r})}$ \\
\hline $\mathrm{G}_{(1)}$ & 21,6 & 13,6 & 33,0 & 21,6 & 13,9 & 29,3 \\
\hline $\mathrm{G}_{(2)}$ & 51,8 & 42,6 & 57,6 & 41,9 & 30,4 & 47,8 \\
\hline $\mathrm{G}_{(3)}$ & 65,3 & 44,4 & 69,9 & 59,7 & 43,1 & 63,8 \\
\hline $\mathrm{G}_{(1, \mathrm{a})}$ & 21,6 & 13,5 & 34,3 & 13,4 & 8,8 & 21,9 \\
\hline $\mathrm{G}_{(1, \mathrm{~b})}$ & 21,7 & 13,7 & 30,7 & 36,7 & 23,3 & 42,8 \\
\hline $\mathrm{G}_{\left(2^{*}\right)}$ & 54,7 & 43,1 & 59,6 & 46,1 & 34,5 & 51,0 \\
\hline $\mathrm{G}_{\left(3^{*}\right)}$ & 80,3 & 45,3 & 88,7 & 74,7 & 44,3 & 83,0 \\
\hline
\end{tabular}


e $\mathrm{G}_{\left(3^{\star}\right)}$ - valores superiores em todos os bioensaios, tanto de Mimosa pudica quanto de Senna obtusifolia, ressaltando-se a exceção anterior (Tabela 3).

Com relação à especificidade, as espécies (i.a) Bauhinia macrostachya e Bowdichia virgiloides apresentaram especificidade efetiva a Mimosa pudica em todos os bioensaios; e (i.b) Swartzia multijuga mostrou especificidade potencial a Mimosa pudica na fração "folha" e especificidade efetiva a Mimosa pudica na fração "raiz". Já (i.c) Parkia pendula apresentou especificidade potencial ou efetiva a Mimosa pudica na inibição de germinação e do alongamento do hipocótilo, enquanto (i.d) Inga edulis apresentou especificidade a Mimosa pudica na inibição à germinação, e sua fração "raiz", a mesma especificidade na inibição do alongamento de radiculas (Tabela 4).

No caso de (ii.a) Bauhinia guianensis, a inibição das radículas foi específica a Mimosa pudica em ambas as frações, enquanto especificidade a Mimosa pudica na germinação foi potencial somente na fração "folha", e a especificidade a Senna obtusifolia no hipocótilo foi potencial na fração "raiz". No caso de (ii.b)
Platimeria reticulata, a germinação foi potencialmente específica a Mimosa pudica na fração "folha" e efetivamente específica a Senna obtusifolia na fração "raiz"; a inibição do hipocótilo foi específica a Senna obtusifolia somente na fração "raiz", e a inibição das radículas foi específica a Mimosa pudica na fração "raiz". A espécie (iii) Dialium guianensis mostrou especificidade efetiva em ambas as frações, em todos os bioensaios, a Senna obtusifolia (Tabela 4).

Com relação à efetividade de inibição dos bioensaios em Mimosa pudica, as (i) espécies Bauhinia guianensis, Bauhinia macrostachya, Bowdichia virgiloides, Parkia pendula e Platimenia reticulata tiveram resposta potencial ou efetiva em todos os bioensaios em ambas as frações constituintes dos extratos. As espécies (ii.a) Dialinum guianensis, fração "folha", e Inga edulis, fração "raiz", apresentaram resposta potencial à inibição do alongamento radicular; (ii.a) Swartzia multijuga apresentou inibição radicular em ambas frações e de germinação na fração "folha" (Tabela 4).

No que se refere à efetividade da inibição em Senna obtusifolia, as (i.a) espécies

Tabela 4 - Quadro sinóptico da especificidade e efetividade da inibição de germinação, do alongamento do hipocótilo e da radícula nos extratos com relação as espécies receptoras Mimosa pudica e Senna obtusifolia

\begin{tabular}{|c|c|c|c|c|c|c|c|c|c|c|}
\hline \multirow{2}{*}{\multicolumn{2}{|c|}{ Extrato }} & \multirow{2}{*}{\multicolumn{3}{|c|}{ Especificidade }} & \multicolumn{6}{|c|}{ Efetividade } \\
\hline & & & & & \multicolumn{3}{|c|}{ Mimosa pudica } & \multicolumn{3}{|c|}{ Senna obtusifolia } \\
\hline Espécie & Fração & {$[\mathrm{G}]$} & {$[\mathrm{H}]$} & {$[\mathrm{R}]$} & {$[\mathrm{G}]$} & {$[\mathrm{H}]$} & {$[\mathrm{R}]$} & {$[\mathrm{G}]$} & {$[\mathrm{H}]$} & {$[\mathrm{R}]$} \\
\hline \multirow{2}{*}{ B. guianensis } & Folhas & $\mathrm{M}(+)$ & & $\mathrm{M}(+)$ & $(++)$ & $(+)$ & $(++)$ & $(++)$ & $(+)$ & $(++)$ \\
\hline & Raízes & & $\mathrm{S}(+)$ & $\mathrm{M}(++)$ & $(++)$ & $(+)$ & $(++)$ & $(++)$ & $(+)$ & $(++)$ \\
\hline \multirow{2}{*}{ B. macrostachya } & Folhas & $\mathrm{M}(++)$ & $\mathrm{M}(++)$ & $\mathrm{M}(++)$ & $(++)$ & $(+)$ & $(++)$ & & & $(+)$ \\
\hline & Raízes & $\mathrm{M}(++)$ & $\mathrm{M}(++)$ & $\mathrm{M}(++)$ & $(++)$ & $(++)$ & $(++)$ & $(++)$ & & $(++)$ \\
\hline \multirow{2}{*}{ B. virgiloides } & Folhas & $\mathrm{M}(++)$ & $\mathrm{M}(++)$ & $\mathrm{M}(++)$ & $(++)$ & $(+)$ & $(++)$ & $(+)$ & & $(++)$ \\
\hline & Raízes & $\mathrm{M}(++)$ & $\mathrm{M}(++)$ & $\mathrm{M}(++)$ & $(+)$ & $(+)$ & $(++)$ & $(+)$ & & $(+)$ \\
\hline \multirow{2}{*}{ D. guianensis } & Folhas & $\mathrm{S}(++)$ & $\mathrm{S}(++)$ & $\mathrm{S}(++)$ & & & $(+)$ & $(+)$ & & $(++)$ \\
\hline & Raízes & $\mathrm{S}(++)$ & $\mathrm{S}(++)$ & $\mathrm{S}(++)$ & & & & $(+)$ & & $(+)$ \\
\hline \multirow{2}{*}{ I. edulis } & Folhas & $\mathrm{M}(+)$ & & & & & & & & \\
\hline & Raízes & $\mathrm{M}(++)$ & & $\mathrm{M}(++)$ & & & $(+)$ & & & \\
\hline \multirow{2}{*}{ P. pendula } & Folhas & $\mathrm{M}(++)$ & $M(+)$ & & $(++)$ & $(++)$ & $(++)$ & $(++)$ & $(+)$ & $(++)$ \\
\hline & Raízes & $\mathrm{M}(+)$ & $\mathrm{M}(++)$ & & $(++)$ & $(++)$ & $(++)$ & $(++)$ & $(+)$ & $(+)$ \\
\hline \multirow{2}{*}{ P. reticulata } & Folhas & $\mathrm{M}(+)$ & & & $(++)$ & $(++)$ & $(++)$ & $(++)$ & $(+)$ & $(++)$ \\
\hline & Raízes & $\mathrm{S}(++)$ & $\mathrm{S}(+)$ & $\mathrm{M}(++)$ & $(+)$ & $(+)$ & $(++)$ & $(++)$ & $(+)$ & $(++)$ \\
\hline \multirow{2}{*}{ S. multijuga } & Folhas & $\mathrm{M}(+)$ & $\mathrm{M}(+)$ & $\mathrm{M}(+)$ & $(+)$ & & $(++)$ & & & $(+)$ \\
\hline & Raízes & $\mathrm{M}(++)$ & $\mathrm{M}(+)$ & $\mathrm{M}(++)$ & & & $(+)$ & & & \\
\hline
\end{tabular}

[G] - inibição da germinação $[\mathrm{H}]$ - inibição do alongamento do hipocótilo; [R] - inibição do alongamento de radículas; $\mathrm{M}$ - Mimosa pudica; S - Senna obtusifolia; $(+)$ - resposta potencial; (++) - resposta efetiva. 
Bauhinia guianensis, Parkia pendula e Platimenia reticulata tiveram resposta potencial ou efetiva em todos os bioensaios em ambas as frações constituintes dos extratos. As (i.b) espécies Bowdichia virgiloides e Dialinum guianensis tiveram resposta potencial ou efetiva em todos os bioensaios, à exceção da inibição do alongamento do hipocótilo. A espécie (ii.a) Bauhinia macrostachya mostrou resposta efetiva na inibição radicular em ambas as frações e na germinação na fração radicular, enquanto (ii.b) Swartzia multijuga apresentou resposta potencial à inibição radicular na fração folha. A espécie (iii) Inga edulis não apresentou resposta a nenhum dos bioensaios em Senna obtusifolia. Desse modo, tem-se potencial alelopático inibitório mais amplo e efetivo nas espécies Bauhinia guianensis, Bowdichia virgiloides, Parkia pendula e Platimenia reticulata. Evidenciou-se, ainda, potencial alelopático efetivo e mais restrito em Bauhinia macrostachya.

Em estudos de alelopatia, a atividade biológica de um dado extrato depende tanto da concentração utilizada como do limite de resposta da espécie receptora. Fatores associados à espécie doadora e à fonte do extrato também contribuem para a maior ou menor atividade observada. Em diferentes estudos, atividade alelopática já foi constatada em sementes, folhas, raizes, flores, rizomas, colmos, vagens e pólen de diferentes espécies de plantas (Tawaha \& Turk, 2003; Rodrigues et al., 2010). Neste trabalho, variações no padrão da atividade alelopática inibitória também ocorreram em função desses aspectos. Em termos globais, a tendência observada foi de as espécies Bauhinia guianensis e Parkia pendula apresentarem efeitos inibitórios mais intensos. As folhas constituíram-se na principal fonte de compostos químicos com atividade alelopática, embora para as espécies Bauhinia macrostachya e Inga edulis os efeitos inibitórios de maior grandeza tenham sido observados nas raízes. Esse resultado mostra que as plantas alocam seus constituintes químicos de forma não padronizada mesmo para espécies de mesma família ou do mesmo gênero, como é o caso, neste trabalho, de Bauhinia guianensis, que apresentou as folhas como principal fonte de aleloquímicos, e de Bauhinia macrostachya, que teve nas raízes a maior atividade inibitória. Em outras espécies de Leguminosae, as sementes foram a principal fonte de atividade alelopática, como nos trabalhos de Souza Filho (2002) e Souza Filho et al. (1999). Pode-se, ainda, aventar a possibilidade de essa relação ser alterada em função de aspectos relacionados à idade da planta, ou seja, em determinada idade, ou momento fisiológico da planta, a atividade alelopática é mais intensa nas folhas; entretanto, com as mudanças na idade da planta, essa atividade é deslocada para outra fração, que tanto pode ser as raízes como outra fação, conforme observado por Souza Filho et al. (2003).

Um ponto que chama a atenção neste trabalho diz respeito às diferenças observadas nas intensidades dos efeitos inibitórios produzidos pelas frações folha e raízes. O padrão observado foi de que as espécies que apresentaram alta atividade alelopática nas folhas também o fazem nas raízes, e essa diferença é maior naquelas espécies que evidenciaram menor atividade. De outra maneira, isso indica que, em espécies de alta atividade alelopática, a tendência é de que elas aloquem o pool de seus constituintes químicos em diferentes frações de forma semelhante, enquanto naquelas de menor atividade as plantas dão preferência majoritária a uma das frações.

Em termos globais, o padrão observado para os efeitos sobre a germinação das sementes e o alongamento da radícula e do hipocótilo indicou o alongamento da radícula, seguido da germinação das sementes, como o mais sensivel aos efeitos alelopáticos dos extratos, independentemente da espécie receptora e da fonte do extrato. Informações semelhantes são observadas nos trabalhos de Souza Filho et al. (2005), Shiraishi et al. (2002) e Arruda et al. (2005).

As espécies de Poaceae estudadas neste trabalho não apresentaram padrão uniforme no tocante à intensidade dos efeitos potenciais alelopáticos. Variações expressivas foram observadas tanto entre as espécies de gêneros diferentes como entre espécies do mesmo gênero. Fatores associados à espécie receptora e aos parâmetros analisados (germinação de sementes e alongamento da radícula) foram determinantes nos padrões de resposta obtidos. Em termos globais, a intensidade do efeito 
potencial alelopático inibitório foi mais ampla e efetiva nas espécies Bauhinia guianensis, Bowdichia virgiloides, Parkia pendula e Platimenia reticulata. Observou-se potencial alelopático efetivo e mais restrito em Bauhinia macrostachya. No tocante ao fator fração das plantas, constatou-se diferenciação no padrão de atividade: para a maioria das espécies, a folha foi a principal fonte de aleloquímicos, e para Bauhinia macrostachya e Inga edulis, a raiz. Em termos de padrão de respostas das espécies receptoras, o alongamento da radícula é mais sensivel aos efeitos dos extratos, ficando o alongamento do hipocótilo como o de menor sensibilidade.

\section{LITERATURA CITADA}

ARRUDA, M. S. P. et al. Potential allelochemicals isolated from Pueraria phaseoloides. Allelopathy J., v. 15, n. 2, p. 211-220, 2005.

BORGES, E. E. L.; LOPES, E. S.; SILVA, G. F. Avaliação de substâncias alelopáticas em vegetação de uma floresta secundária. 1. Árvores. R. Árvore, v. 17, n. 1, p. 69-84, 1993.

CHOU, C. H. Allelopathic in relation to agricultural productivity in Taiwan: problem and prospects. In: RIZVI, S. J. H.; RIZVI, V. Allelopathy. New York: Chapmam \& Hill, 1992. p. 179-203.

DUKE, S. O. et al. Chemical from nature for weed management. Weed Sci., v. 50, p. 138-151, 2002.

DURAN, J. M.; TORTOSA, M. E. The effect of mechanical and chemical scarification on germination of charlock (Sinapis arvensis L.) seeds. Seed Sci. Technol., v. 13, n. 1, p. 155-163, 1985.

GONZÁLES, L.; SOUTO, X. C.; REIGOSA, M. J. Allelopathic effects of Acacia melanoxyçon R.Br. phyloides during their decomposition. For. Ecol. Manag., v. 77, n. 1-3, p. $53-63,1995$.

INOUE, M. H. et al. Extratos aquosos de Xylopia aromatica e Annona crassiflora sobre capim-marandu (Brachiaria brizantha) e soja. Sci. Agr., v. 10, n. 3, p. 245-250, 2009.

IQBAL, Z.; FURUBAYASHI, A.; FUJI, Y. Allelopathic effects of leaf debris, leaf aqueous extract and rhizosphere soil of Ophiopogon japonicus Ker-Gaweler on the growth of plants. Weed Biol. Manag., v. 4, n. 1, p. 43-48, 2004.

JUNTLA, O. Seed and embryo germination in S. vulgaris and $S$. reflexa as effected by temperature during seed development. Physiol. Plant., v. 29, p. 264-268, 1976.

KATO-NOGUCHI, H. Allelopathic potential of Pueraria thumbergiana. Biol. Plant., v. 47, n. 3, p. 471-473, 2003.
LÔBO, L. T. et al. Potencial alelopático de catequinas de Tachigali myrmecophyla (Leguminosae). Quím. Nova, v. 31, n. 3, p. 493-497, 2008.

PERIOTTO, F. et al. Efeito alelopático de Andira humilis Mart. Ex. Benth na germinação e no crescimento de Lactuca sativa L. e Raphanus sativa L. Acta Bot. Bras., v. 18, n. 3, p. 425-430, 2004.

RODRIGUES, I. M. C. et al. Prospecção química de compostos produzidos por Senna alata com atividade alelopática. Planta Daninha, v. 28, n. 1, p. 1-12, 2010.

SHIRAISHI, S. et al. Allelopathic activity of leaching from dry leaves and exudate from roots of ground cover plants assayed on agar. Weed Biol. Manag., v. 2, p. 133-142, 2002.

SIMÕES, K. et al. Phytotoxic catechin leached by seeds of the tropical weed Seabania virgata. J. Chem. Ecol., v. 34, p. 631-687, 2008.

SOUZA FILHO, A. P. S. Atividade potencialmente alelopática de extratos brutos e hidroalcoólico de feijão-deporco (Canavalia ensiformis). Planta Daninha, v. 20, n. 3, p. 357-364, 2002.

SOUZA FILHO, A. P. S.; FONSECA, M. L.; ARRUDA, M. S. P. Substâncias químicas com atividades alelopáticas presentes nas folhas de Parkia pendula (Leguminosae). Planta Daninha, v. 23, n. 4, p. 565-573, 2005.

SOUZA FILHO, A. P. S.; ALVES, S. M.; FIGUEIREDO, F. J. C. Efeitos alelopáticos do calopogônio em função de sua idade e da densidade de sementes da planta receptora. Planta Daninha, v. 21, n. 2, p. 211-218, 2003.

SOUZA FILHO, A. P. S.; ALVES, S. M. Potencial alelopático de plantas de acapu (Vouacapoua americana): efeitos sobre plantas daninhas de pastagens. Planta Daninha, v. 18, n. 3, p. $435-441,2000$.

SOUZA FILHO, A. P. S. et al. Effects of aqueous extracts of leucaena on germination and radicle elongation of three forage grasses. In: MACIAS, F. A. et al. Recent advances in allelopathy: a science for the future. Cádiz: International Allelopathy Society, 1999. p. 393-396.

TAWATA, A. M.; TURK, M. A. Allelopathic effects of black mustard (Brassica nigra) on germination and growth of barley (Hordeum spontaneum). J. Agron. Crop Sci., v. 189,n. 5, p. 298-303, 2003.

TEFERA, T. Allelopathic effects of Parthenium hysterophorus extracts on seed germination and seedling growth of Eragrostis tef. J. Agron. Crop Sci., v. 188, n.5, p. 306-310, 2002.

XUAN, T. D.; TSUZUKI, E. Varietal differences in allelopathic potential of alfafa. J. Agron. Crop Sci., v. 188, n. 1, p. 2-7, 2002.

ZHANG, O. Potential role allelopathy in the soil and the composing root of chinese-fir replant woodland. Plant Soil, v. 151, n. 2 , p. $205-210,1993$. 